\title{
Correction to: Are soils beneath coniferous tree stands more acidic than soils beneath deciduous tree stands?
}

\author{
Jason R. Burgess-Conforti ${ }^{1}$ - Philip A. Moore $\mathrm{Jr}^{2}$ • Phillip R. Owens ${ }^{3}$ - David M. Miller ${ }^{4}$ - Amanda J. Ashworth ${ }^{2}$. \\ Phillip D. Hays ${ }^{5} \cdot$ Michelle A. Evans-White $^{6} \cdot$ Kelsey R. Anderson ${ }^{4}$
}

Published online: 22 April 2019

(C) Springer-Verlag GmbH Germany, part of Springer Nature 2019

\section{Correction to: Environmental Science and Pollution Research https://doi.org/10.1007/s11356-019-04883-y}

Fig. 1. was amended to reduce the size of the map and improve formatting of the manuscript. The authors claim this amendment does not affect the information being conveyed.

The online version of the original article can be found at https://doi.org/ 10.1007/s11356-019-04883-y

Jason R. Burgess-Conforti

jrburges@uark.edu

1 Environmental Dynamics Program, University of Arkansas,

Fayetteville, AR 72701, USA

2 USDA-ARS, Poultry Production and Product Safety Research Unit, Fayetteville, AR, USA

3 USDA-ARS, Dale Bumpers Small Farms Research Center, Booneville, AR, USA

4 Department of Crop, Soil, and Environmental Sciences, University of Arkansas, Fayetteville, AR, USA

5 U.S. Geological Survey, Arkansas Water Science Center, Fayetteville, AR, USA

6 Biological Sciences Department, University of Arkansas, Fayetteville, AR, USA 
Fig. 1 Locations of the 10 sampling sites within the Ozark National Forest, Arkansas

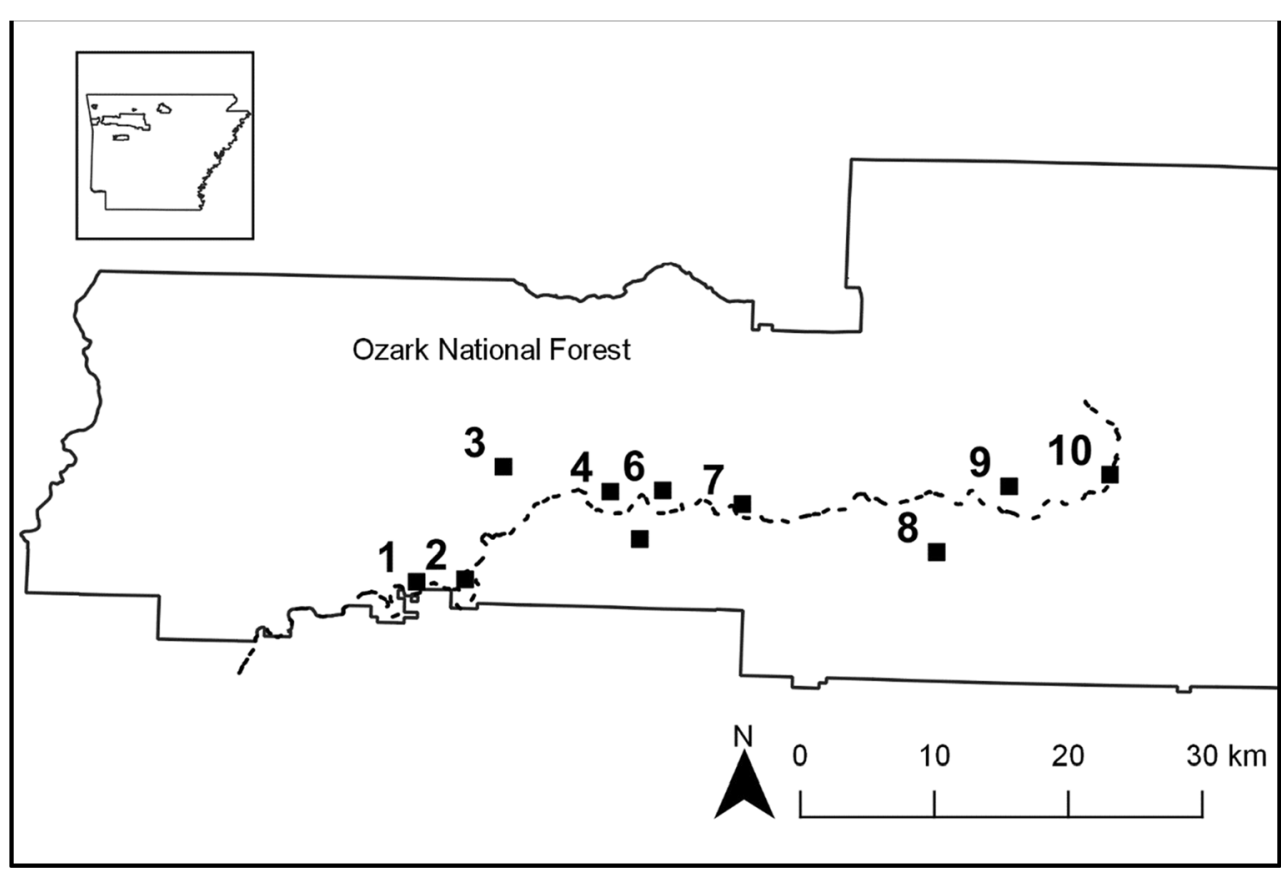

Publisher's note Springer Nature remains neutral with regard to jurisdictional claims in published maps and institutional affiliations. 